Supplement of Hydrol. Earth Syst. Sci., 22, 1713-1729, 2018

https://doi.org/10.5194/hess-22-1713-2018-supplement

(C) Author(s) 2018. This work is distributed under

the Creative Commons Attribution 4.0 License.

(c) (1)

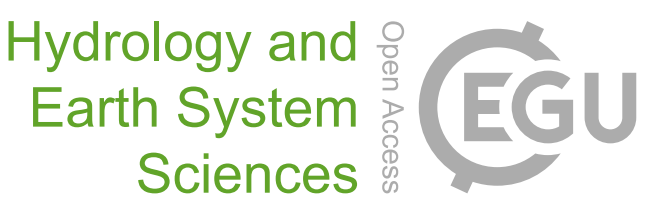

Supplement of

\title{
Hydraulic characterisation of iron-oxide-coated sand and gravel based on nuclear magnetic resonance relaxation mode analyses
}

\section{Stephan Costabel et al.}

Correspondence to: Stephan Costabel (stephan.costabel@bgr.de)

The copyright of individual parts of the supplement might differ from the CC BY 4.0 License. 

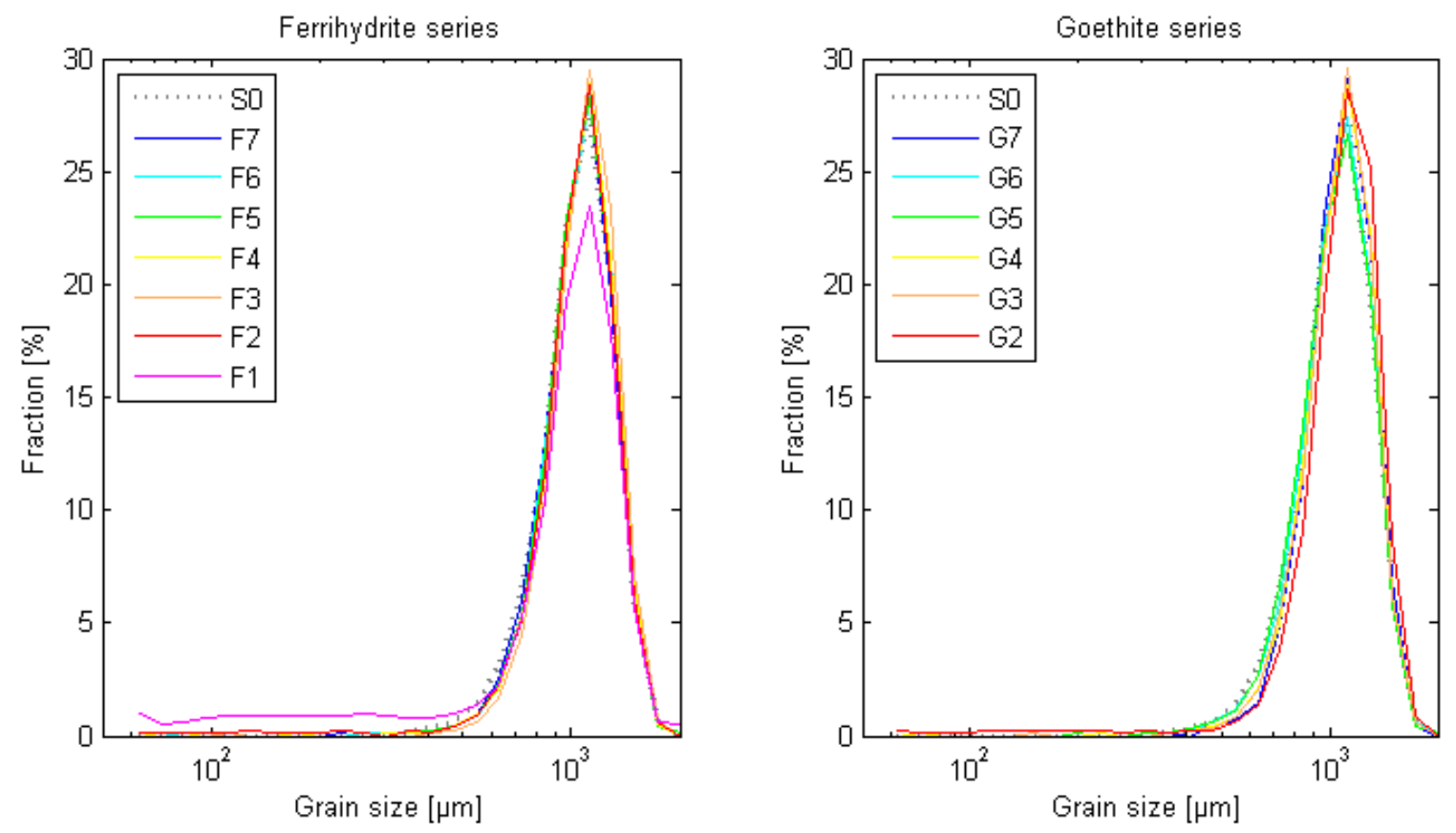

Figure S1: Grain size distributions of (a) the ferrihydrate-coated and (b) the goethite-coated samples. 

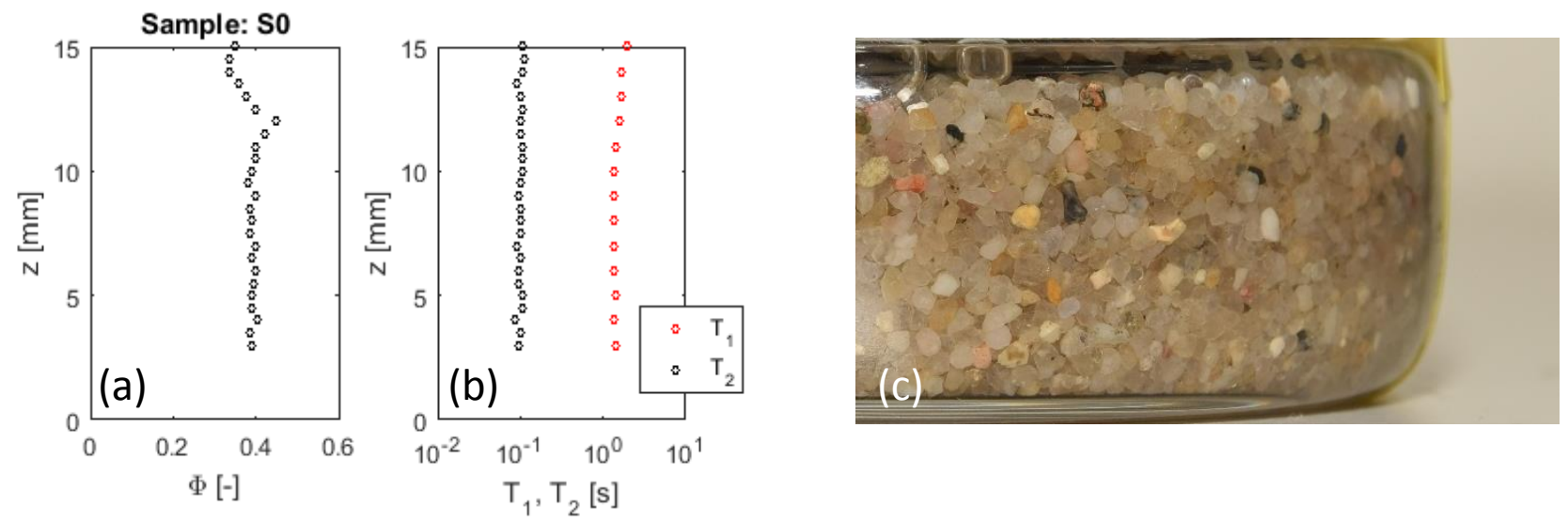

Figure S2: Distributions of (a) NMR porosity and (b) mean relaxation times of initial sand sample S0 (c).
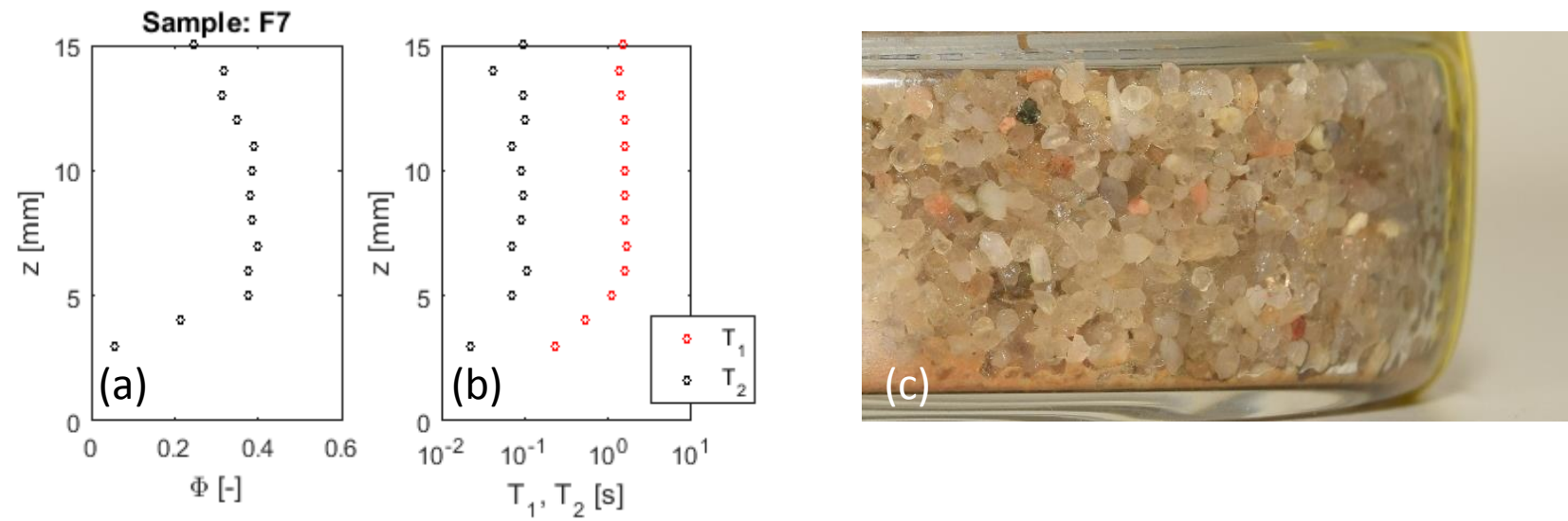

Figure S3: Distributions of (a) NMR porosity and (b) mean relaxation times of sample F7 after precipitation of ferrihydrite (c).
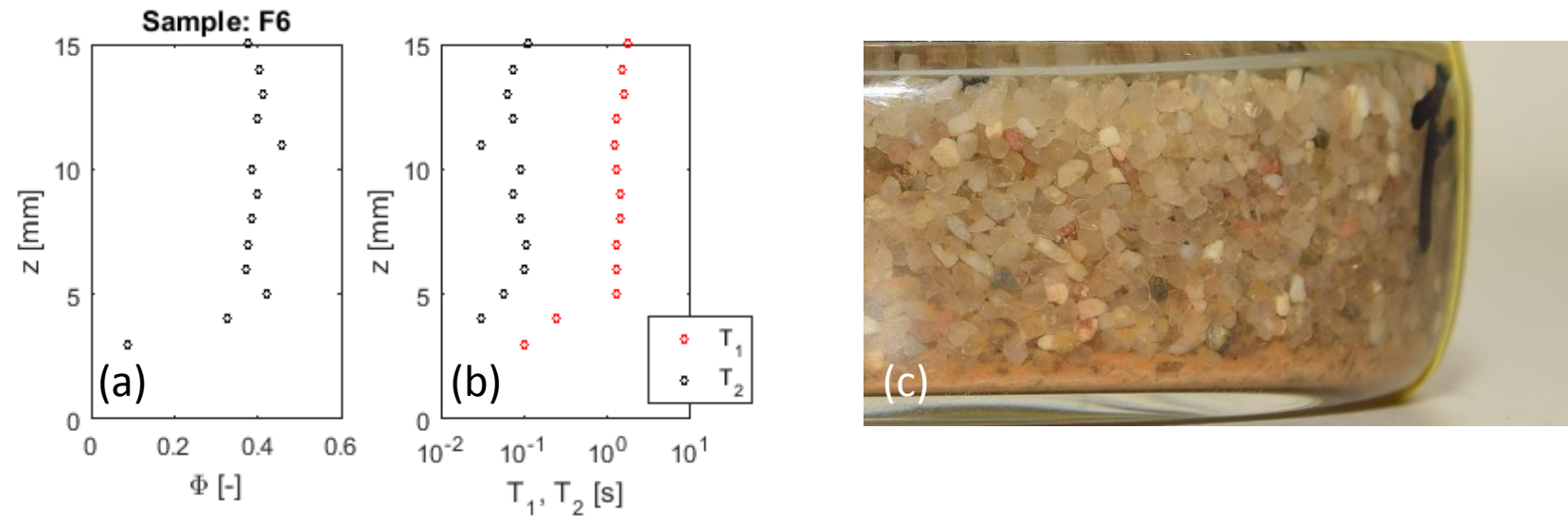

Figure S4: Distributions of (a) NMR porosity and (b) mean relaxation times of sample F6 after precipitation of ferrihydrite (c).
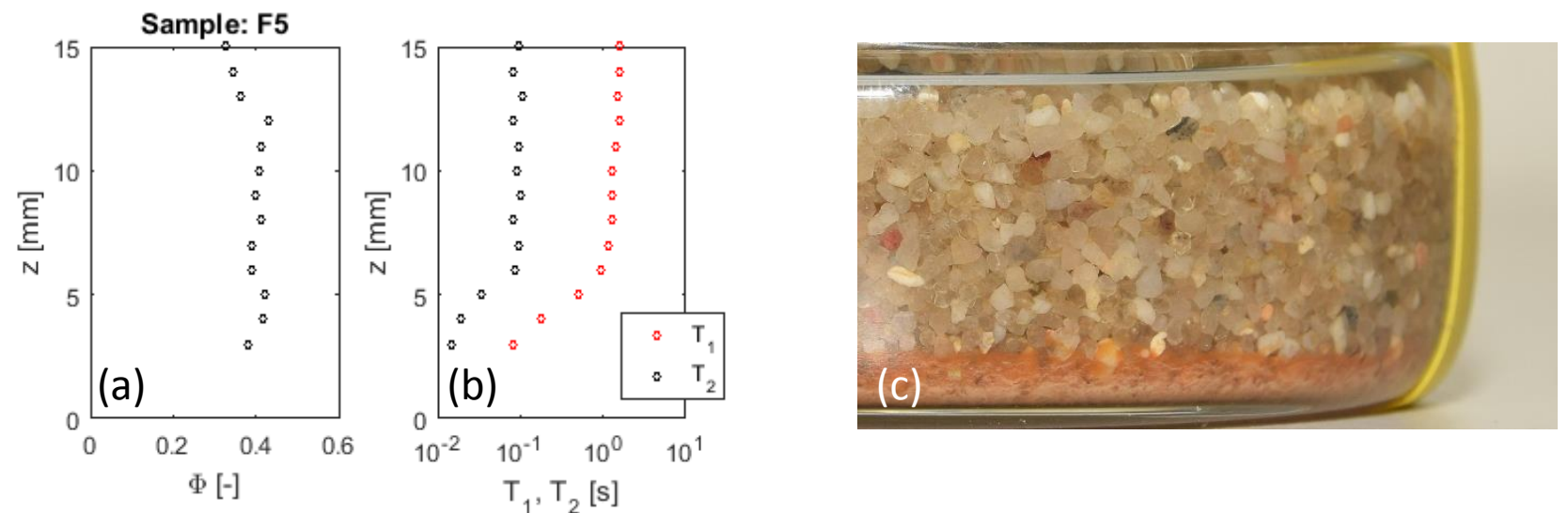

Figure S5: Distributions of (a) NMR porosity and (b) mean relaxation times of sample F5 after precipitation of ferrihydrite (c). 

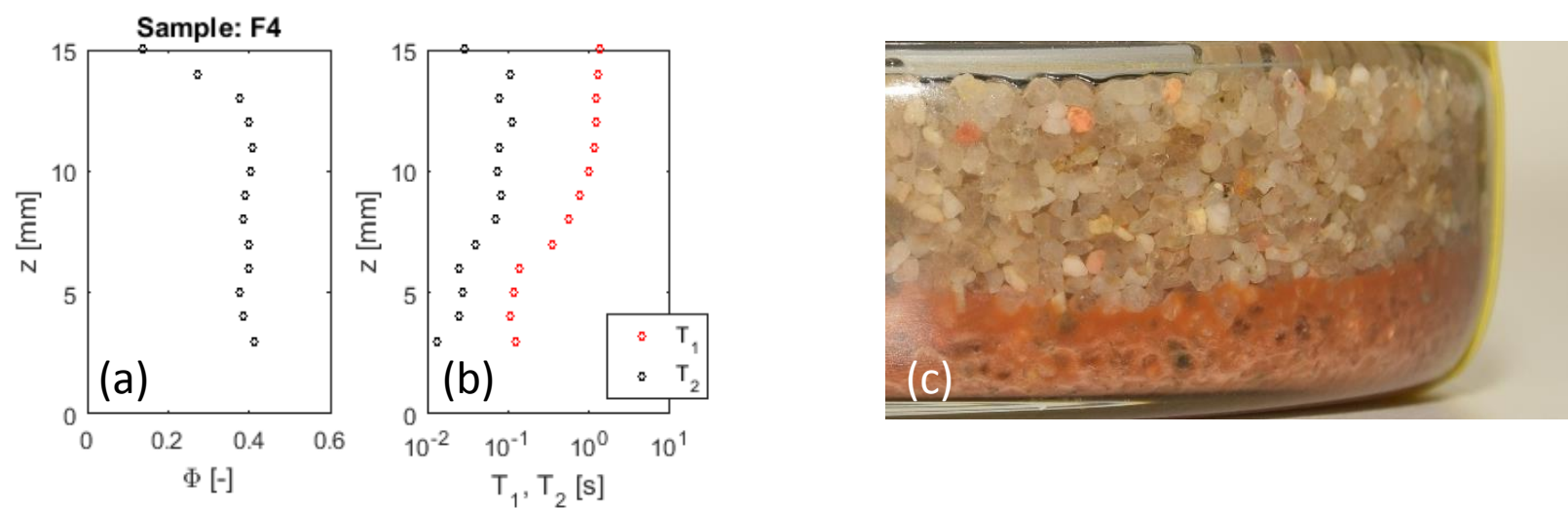

Figure S6: Distributions of (a) NMR porosity and (b) mean relaxation times of sample F4 after precipitation of ferrihydrite (c).
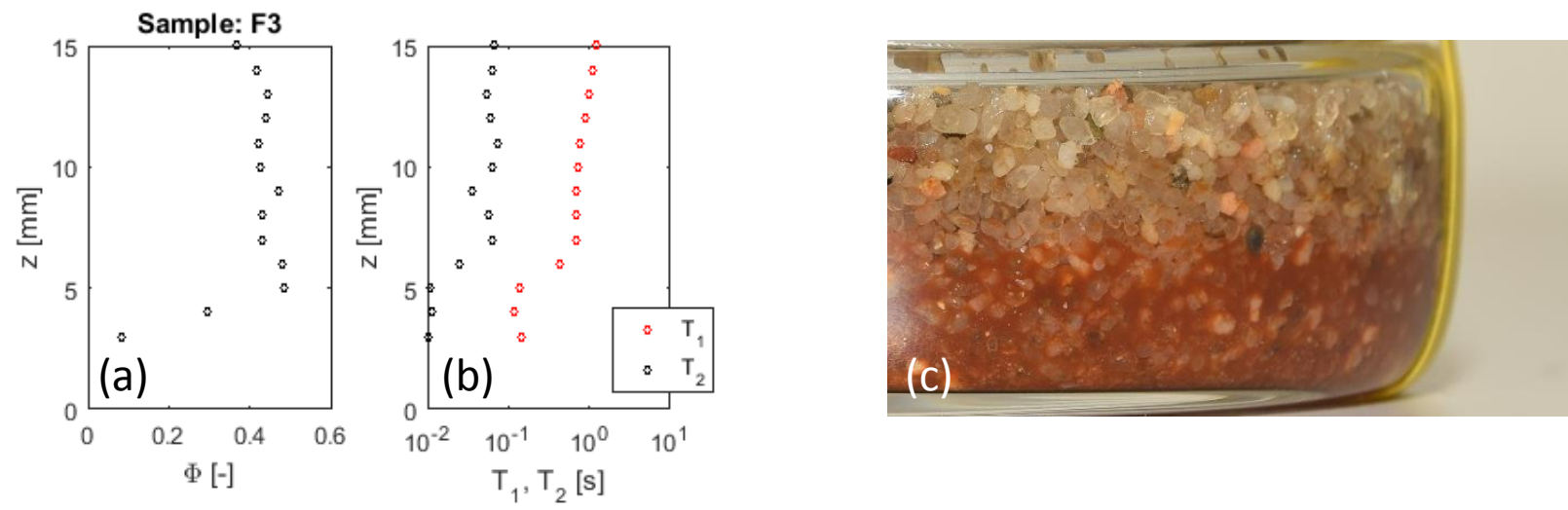

Figure S7: Distributions of (a) NMR porosity and (b) mean relaxation times of sample F3 after precipitation of ferrihydrite (c).
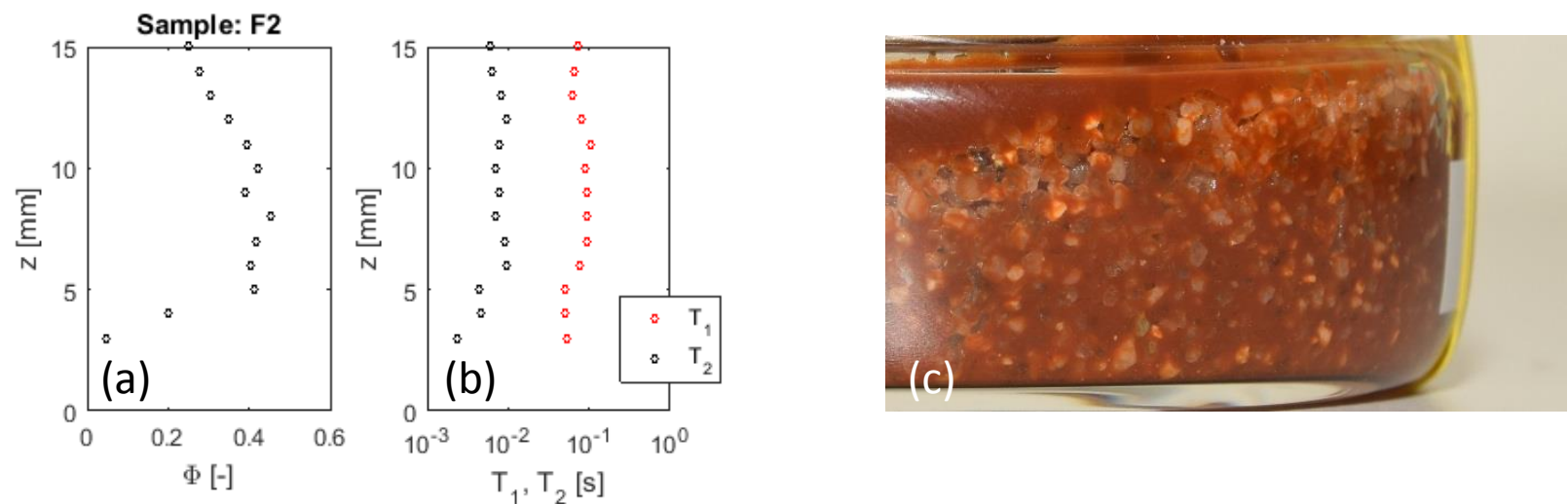

Figure S8: Distributions of (a) NMR porosity and (b) mean relaxation times of sample F2 after precipitation of ferrihydrite (c). Please note the range of X-axis which differs from Fig. S0 - S6.
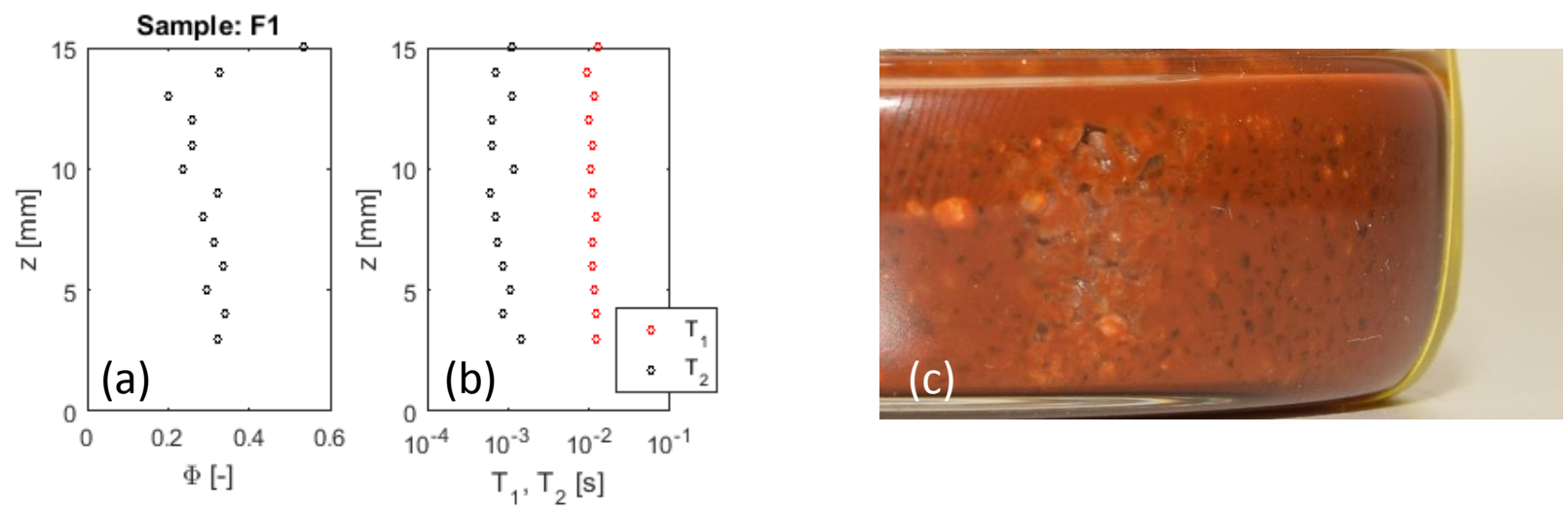

Figure S9: Distributions of (a) NMR porosity and (b) mean relaxation times of sample F1 after precipitation of ferrihydrite (c). Please note the range of $\mathrm{x}$-axis which differs from Fig. S0 - S7. 

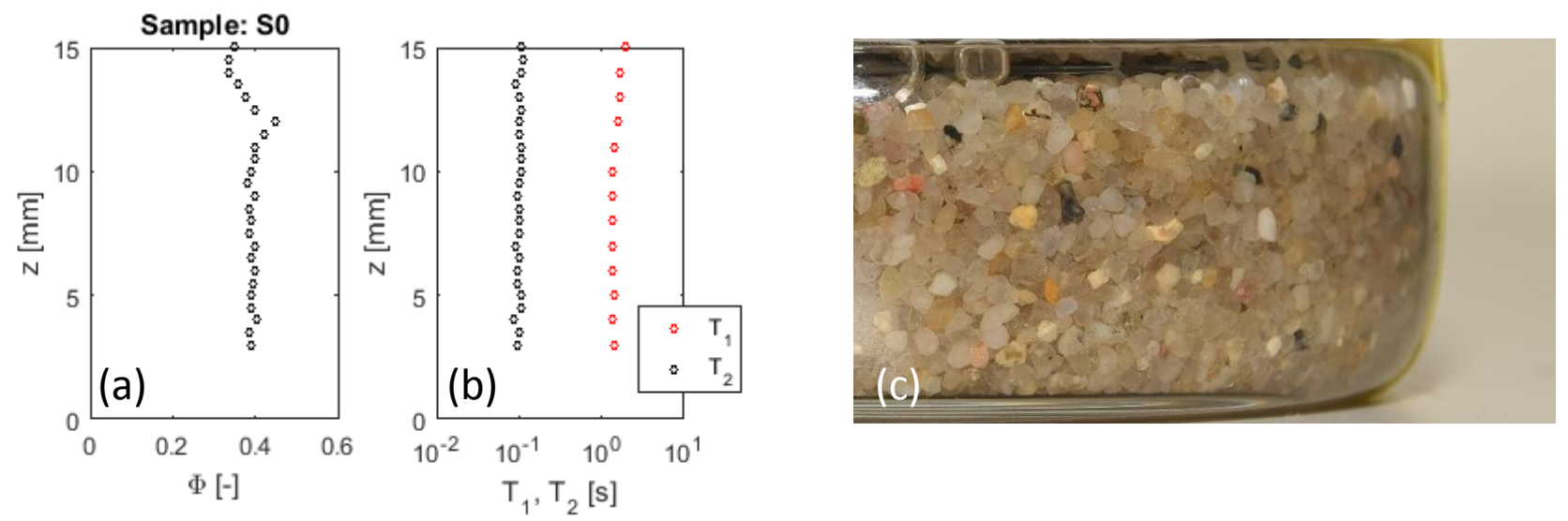

Figure S10: Distributions of (a) NMR porosity and (b) mean relaxation times of initial sand sample S0 (c).
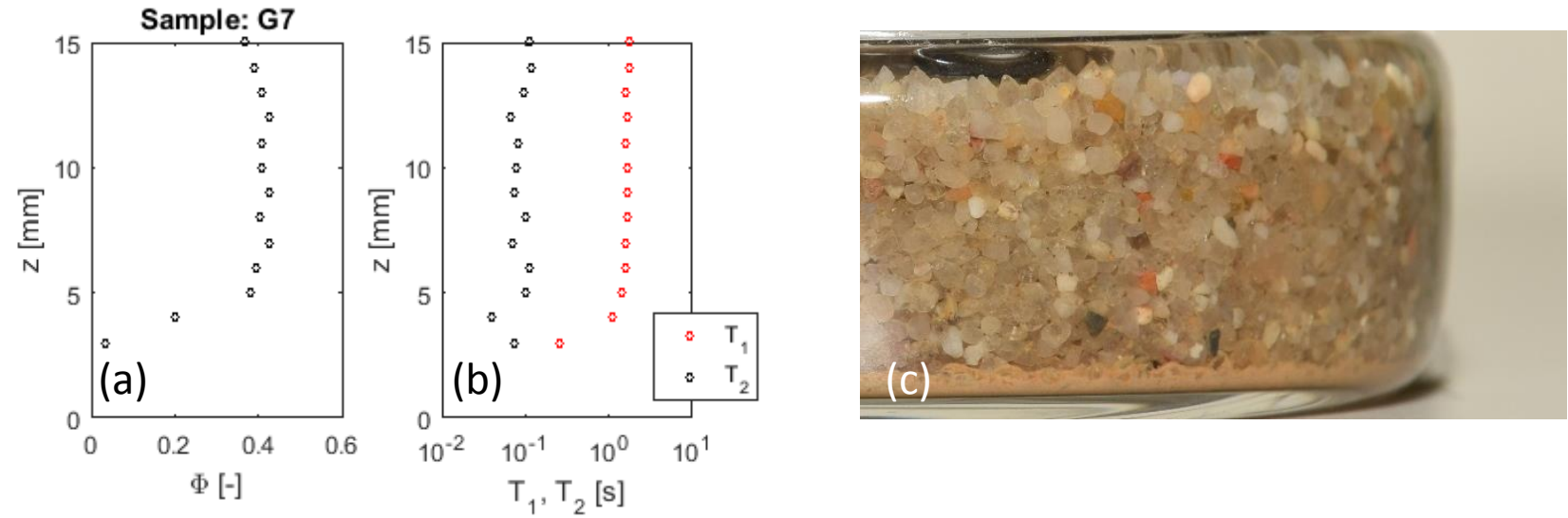

Figure S11: Distributions of (a) NMR porosity and (b) mean relaxation times of sample G7 after precipitation of goethite (c).
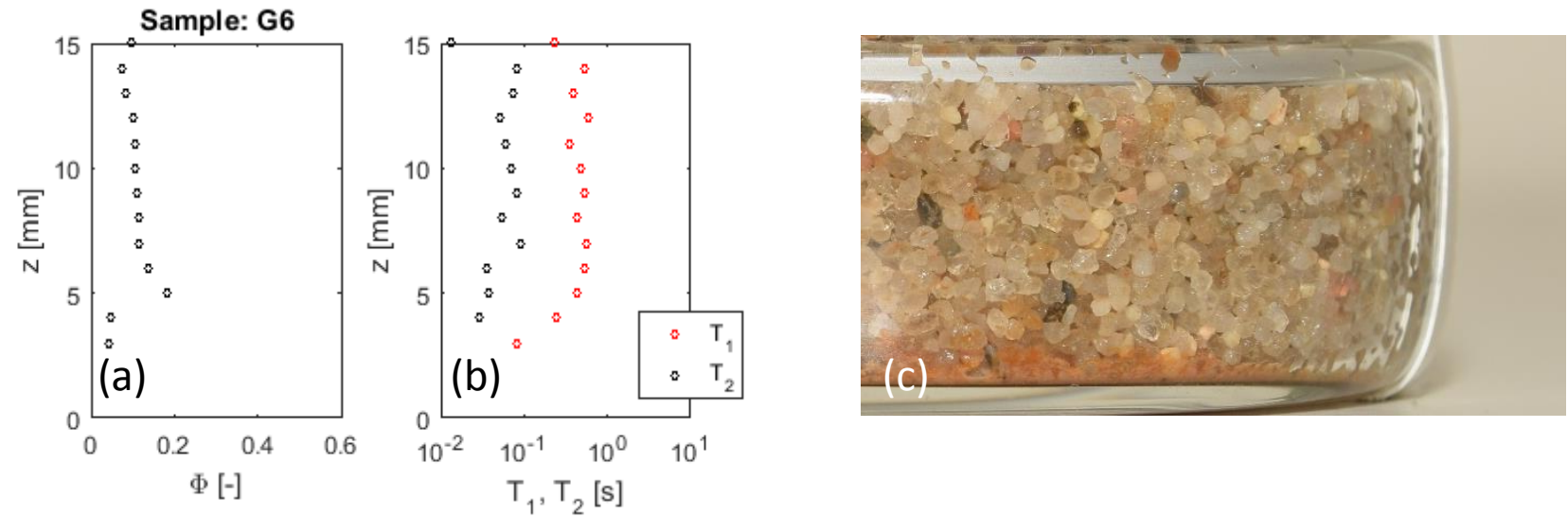

Figure S12: Distributions of (a) NMR porosity and (b) mean relaxation times of sample G6 after precipitation of goethite (c). Please note that the sample almost dried out due to imperfect sealing.
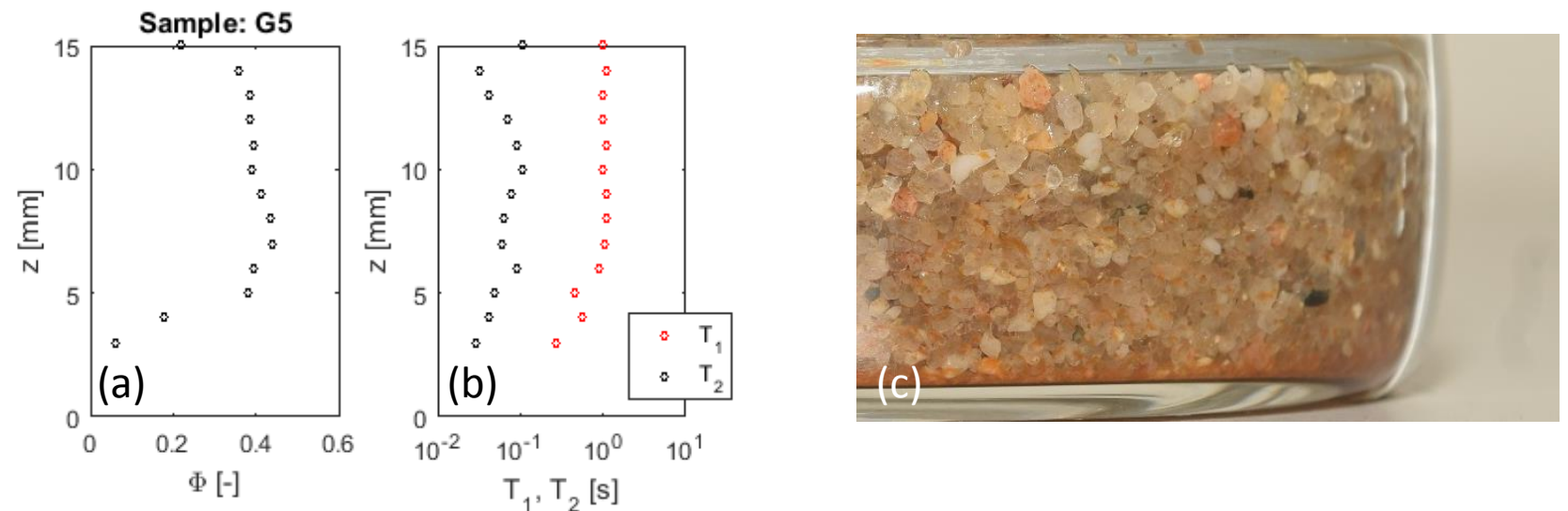

Figure S13: Distributions of (a) NMR porosity and (b) mean relaxation times of sample G5 after precipitation of goethite (c). 

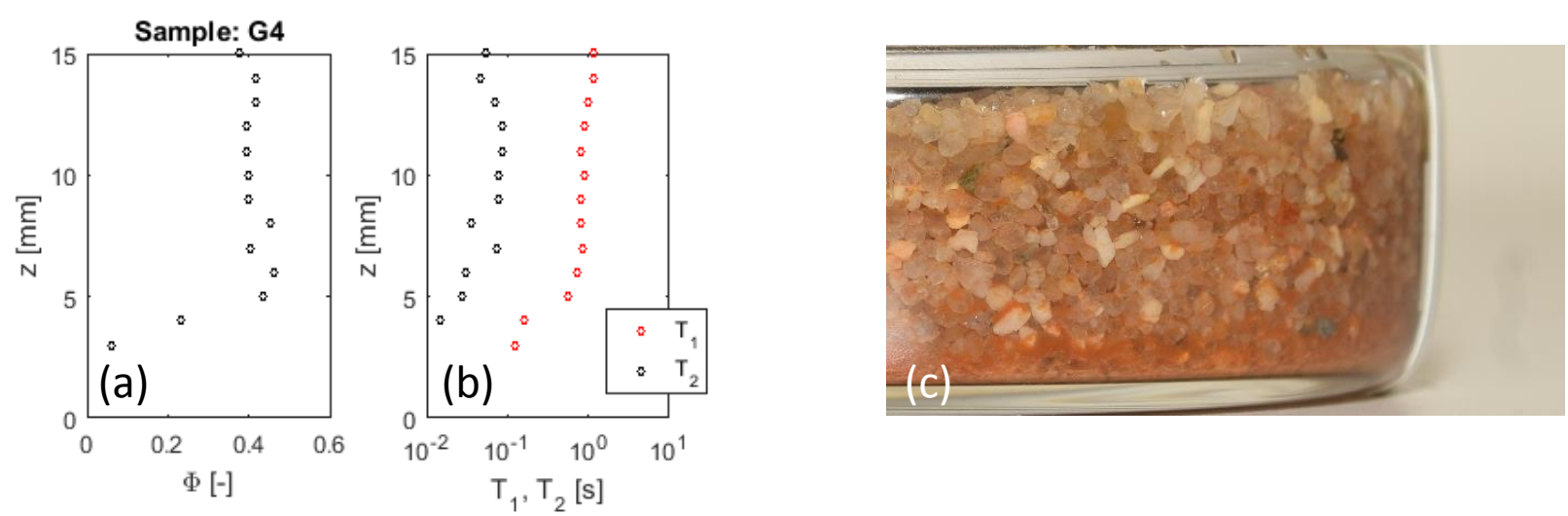

Figure S14: Distributions of (a) NMR porosity and (b) mean relaxation times of sample G4 after precipitation of goethite (c).

Figure S15: Sample G3 after precipitation of goethite. Sample dried out completely due to imperfect sealing (reliable NMR measurements were possible after homogenisation only).
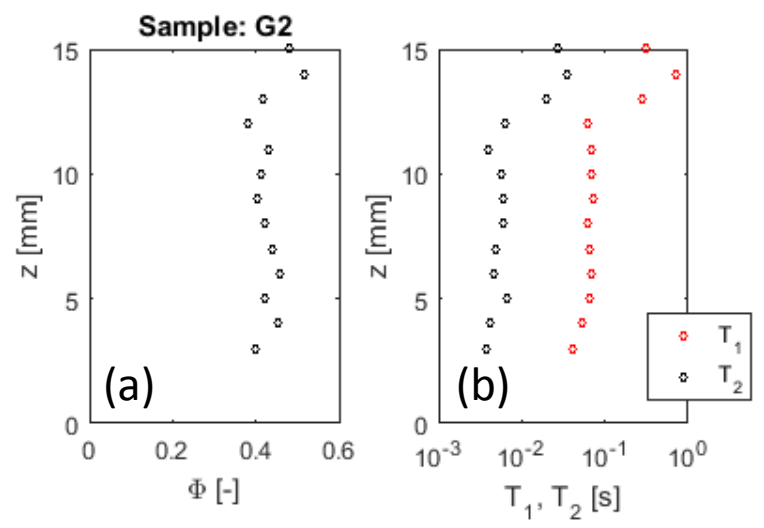

Figure S16: Distributions of (a) NMR porosity and (b) mean relaxation times of sample G2 after precipitation of goethite (a photograph was not taken). Please note the range of $x$-axis which differs from Fig. S9 - S13. 

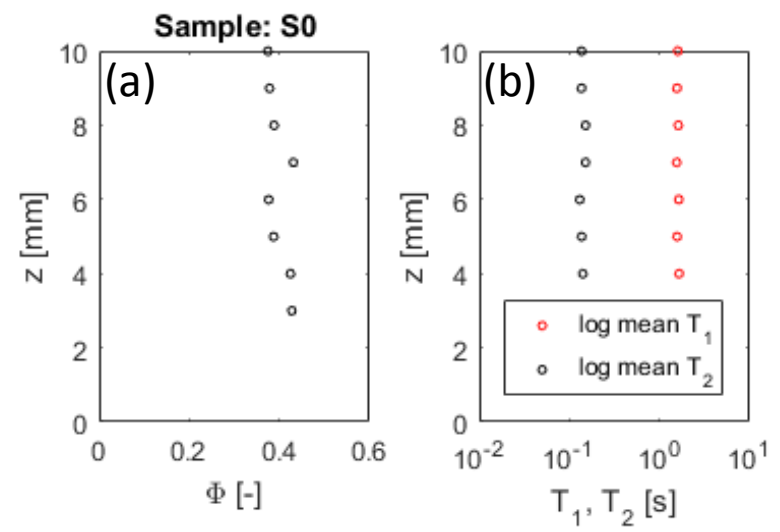

Figure S17: Distributions of (a) NMR porosity and (b) mean relaxation times of initial sand sample S0.
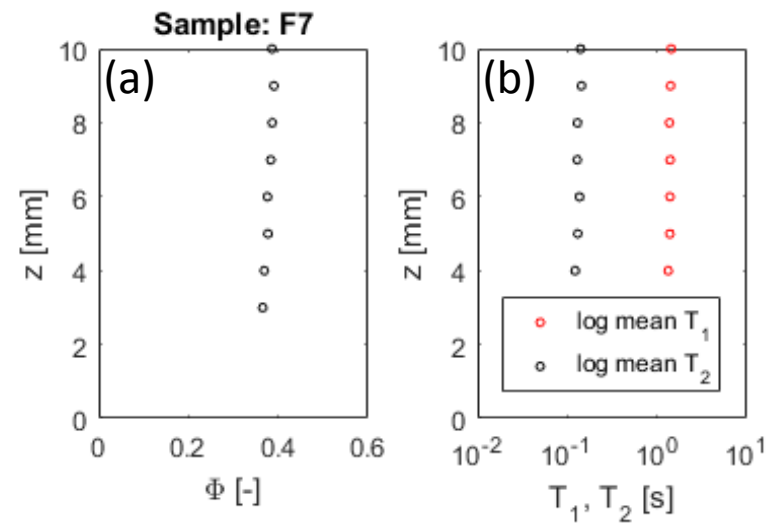

Figure S18: Distributions of (a) NMR porosity and (b) mean relaxation times of sample F7 after precipitation of ferrihydrite and subsequent homogenisation.
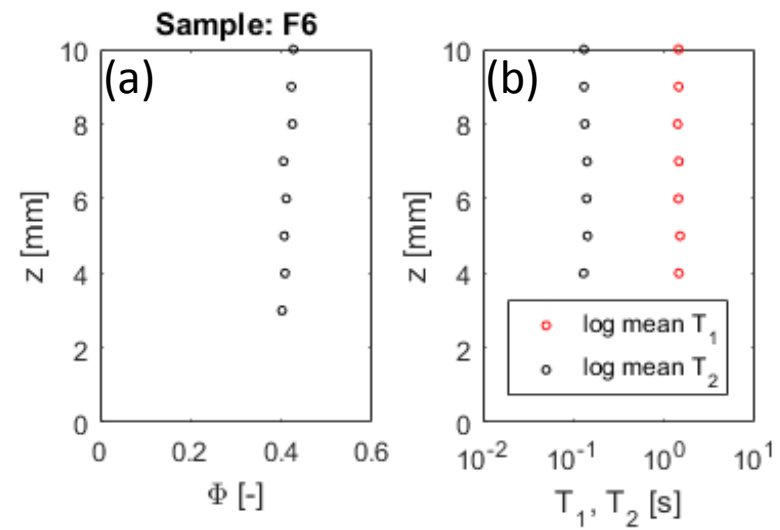

Figure S19: Distributions of (a) NMR porosity and (b) mean relaxation times of sample F6 after precipitation of ferrihydrite and subsequent homogenisation.
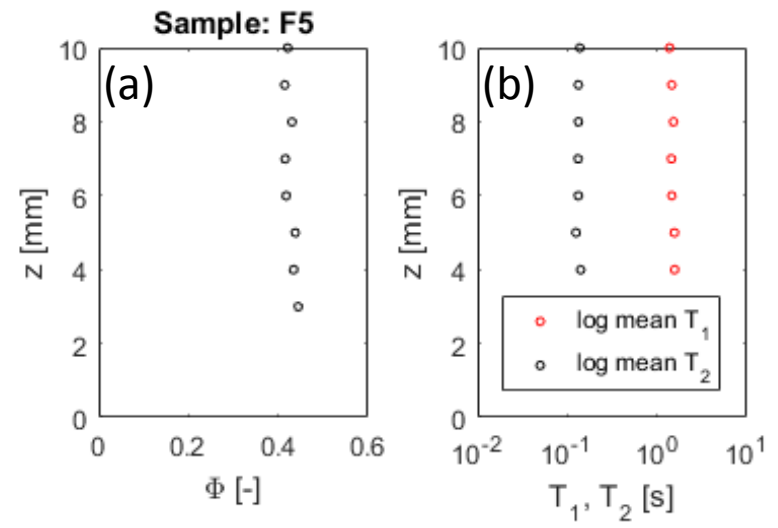

Figure S20: Distributions of (a) NMR porosity and (b) mean relaxation times of sample F5 after precipitation of ferrihydrite and subsequent homogenisation. 

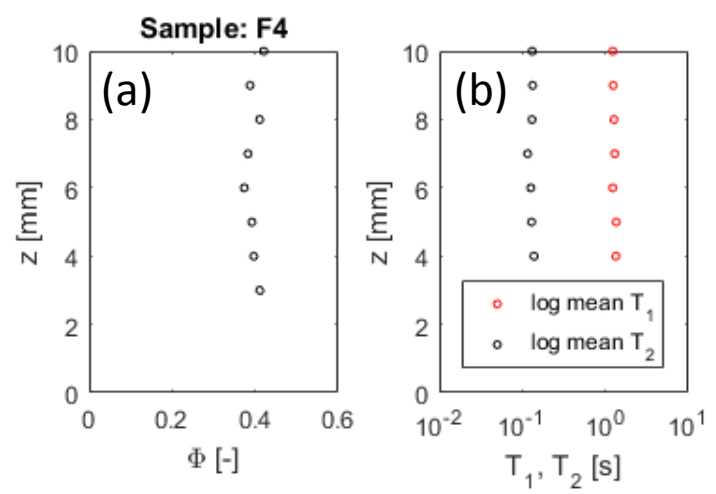

Figure S21: Distributions of (a) NMR porosity and (b) mean relaxation times of sample F4 after precipitation of ferrihydrite and subsequent homogenisation.
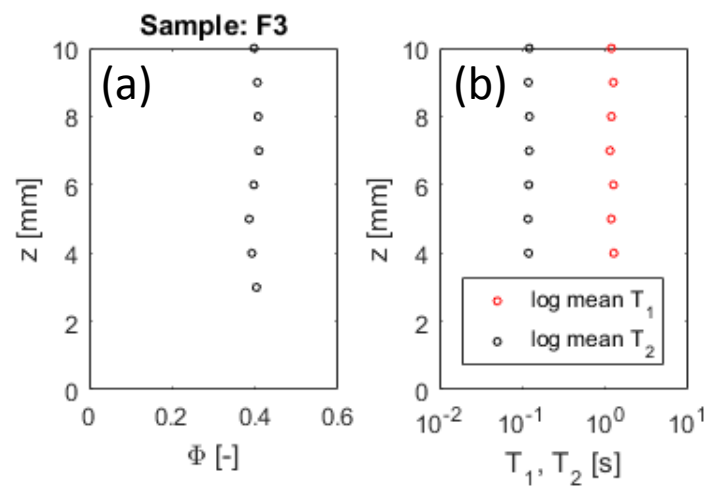

Figure S22: Distributions of (a) NMR porosity and (b) mean relaxation times of sample F3 after precipitation of ferrihydrite and subsequent homogenisation.
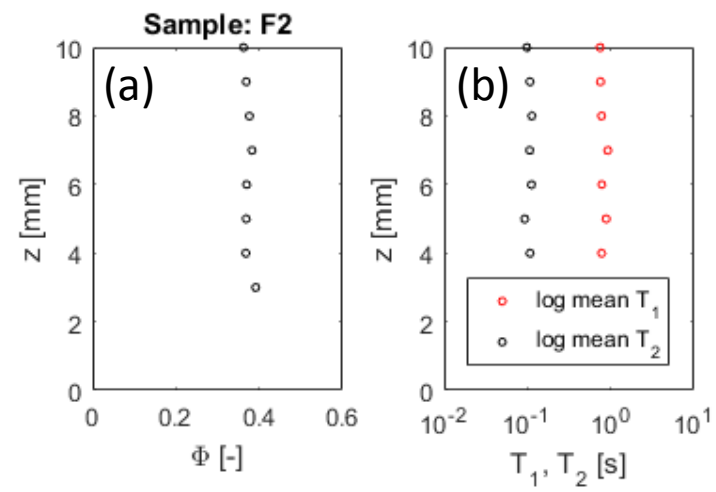

Figure S23: Distributions of (a) NMR porosity and (b) mean relaxation times of sample F2 after precipitation of ferrihydrite and subsequent homogenisation.
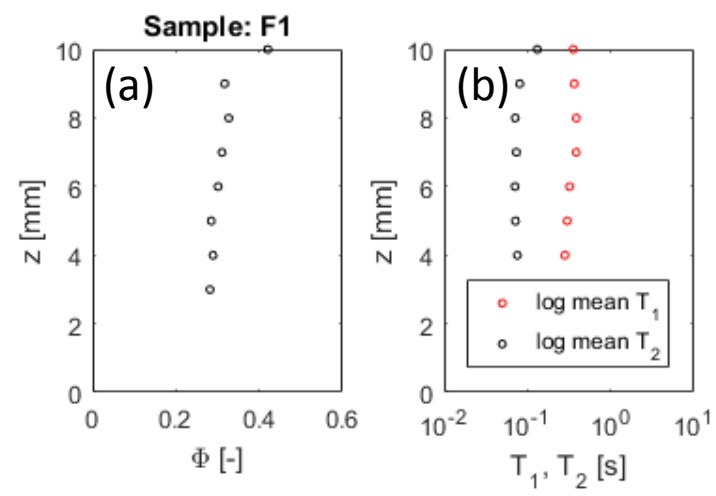

Figure S24: Distributions of (a) NMR porosity and (b) mean relaxation times of sample F1 after precipitation of ferrihydrite and subsequent homogenisation. 
Sample: S0
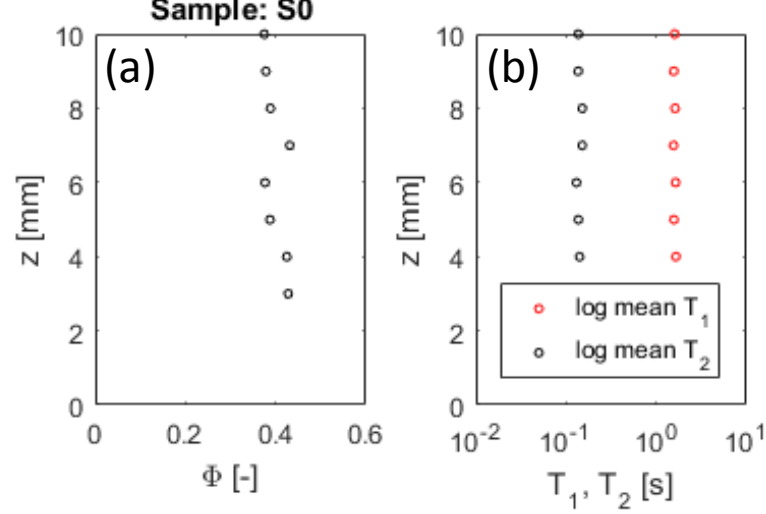

Figure S25: Distributions of (a) NMR porosity and (b) mean relaxation times of initial sand sample S0.
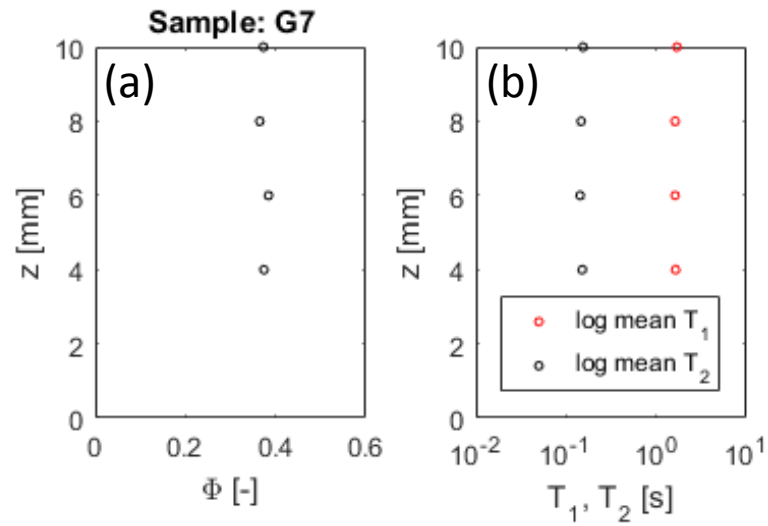

Figure S26: Distributions of (a) NMR porosity and (b) mean relaxation times of sample G7 after precipitation of goethite and subsequent homogenisation.
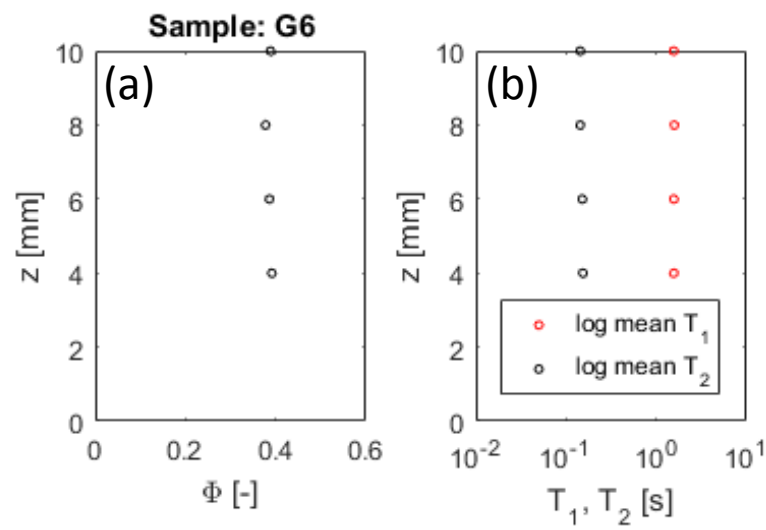

Figure S27: Distributions of (a) NMR porosity and (b) mean relaxation times of sample G6 after precipitation of goethite and subsequent homogenisation.
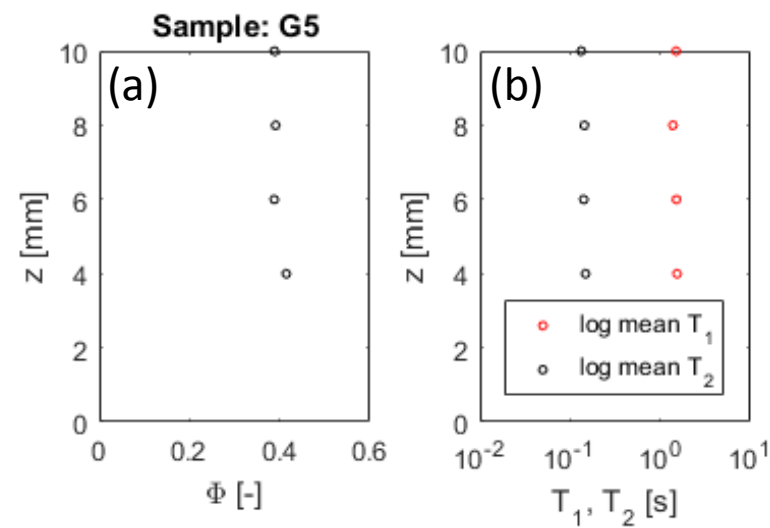

Figure S28: Distributions of (a) NMR porosity and (b) mean relaxation times of sample G5 after precipitation of goethite and subsequent homogenisation. 

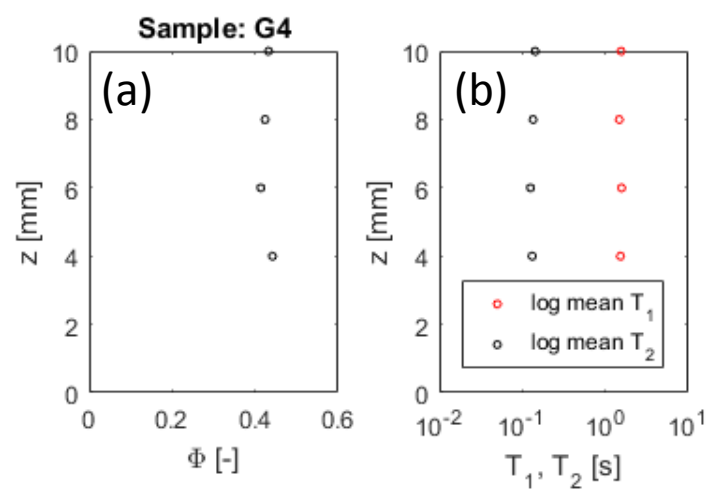

Figure S29: Distributions of (a) NMR porosity and (b) mean relaxation times of sample G4 after precipitation of goethite and subsequent homogenisation.
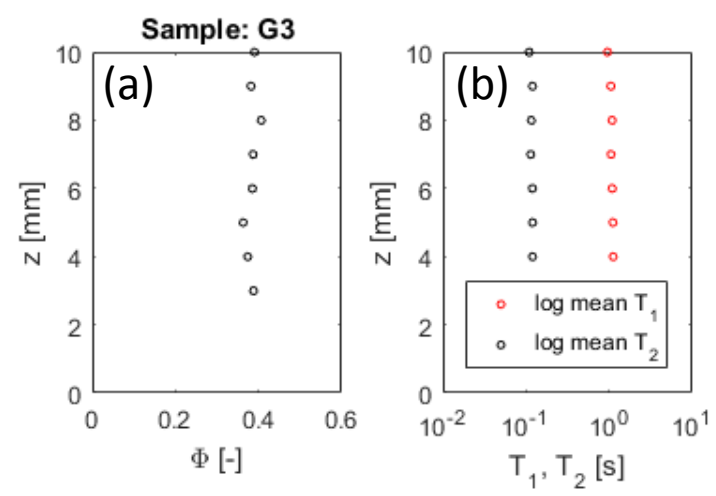

Figure S30: Distributions of (a) NMR porosity and (b) mean relaxation times of sample G3 after precipitation of goethite and subsequent homogenisation.
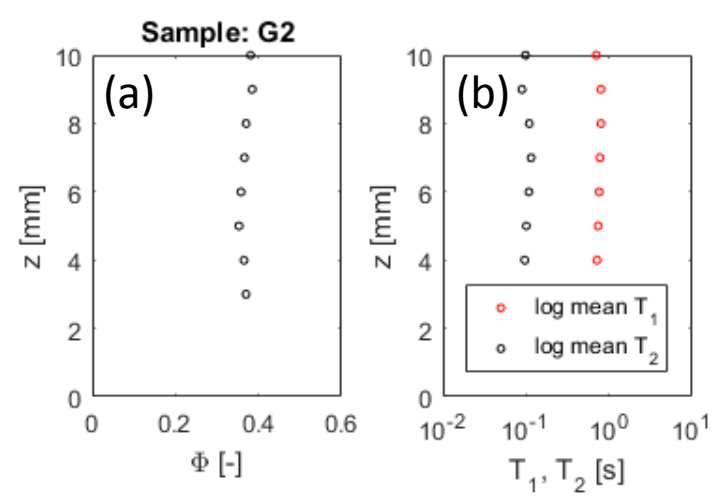

Figure S31: Distributions of (a) NMR porosity and (b) mean relaxation times of sample G2 after precipitation of goethite and subsequent homogenisation. 